\title{
COMPREENSÃO DO BINÔMIO SEGURANÇA E RISCO: PERSPECTIVAS EM DIÁLOGO
}

\author{
Comprehension of the security and risk binomial: perspectives in dialogue \\ Compreensión del binómio seguridad y riesgo: perspectivas en diálogo
}

Rafael Cidrão Campos JoÃo Vitor Moreira Maia

\begin{abstract}
Resumo: O trabalho busca elaborar uma compreensão sobre os ajustamentos criativos de manutenção do status quo e da segurança e a impossibilidade ou inexistência da segurança enquanto ausência de riscos. Apesar dessa impossibilidade, a procura pela segurança e a evitação de riscos são marcantes na sociedade contemporânea e frequentemente se apresentam na clínica psicológica. Esta, muitas vezes, é entendida como um espaço que irá fornecer respostas e segurança tanto no imaginário de quem busca como de quem oferece o serviço psicoterapêutico. Refletindo sobre a temática, busca-se estabelecer um diálogo entre perspectivas sociológicas, a filosofia de Paul Tilich e os referenciais teóricos da Gestalt-terapia. Discute-se que, a partir das sociedades modernas, os saberes científicos, entre eles a Psicologia, são buscados como uma promessa de segurança. Aponta-se, a partir da obra de Paul Tilich, o risco como inerente à existência, ilustrado pela certeza da morte. Indica-se ainda que a ansiedade é vivida pelo homem diante da consciência de sua finitude, sendo essa ansiedade podendo ser enfrentada por um ato de coragem. Recorre-se ao referencial teórico da Gestalt-terapia, que considera a fantasia de segurança e evitação do risco como possíveis ajustamentos neuróticos, entendidos como obstáculos ao crescimento pela evitação do contato com a novidade. Observa também que a prática clínica da Gestalt-terapia não se propõe a oferecer uma ausência de riscos aos seus clientes, mas sim, amparada pelo suporte ambiental construído na relação terapêutica, busca facilitar o contato com a forma como esses riscos são vividos, possibilitando assim o desenvolvimento do autossuporte.
\end{abstract}

Palavras-chave: Segurança; Risco; Gestalt-terapia.

\begin{abstract}
The paper seeks to develop an understanding of the creative adjustments of maintaining the status quo and security and the impossibility or non-existence of security as risk-free. Despite this impossibility, the search for safety and risk avoidance are striking in contemporary society and often present in the psychological clinic. This is often understood as a space that will provide answers and security in the imagination of both the seeker and the psychotherapist. Reflecting on the subject, we seek to establish a dialogue between sociological perspectives, the philosophy of Paul Tilich and the theoretical references of Gestalt Therapy. It is argued that, from modern societies, scientific knowledge, including psychology, is sought as a promise of security. From Paul Tilich's work, risk is pointed out as inherent in existence, illustrated by the certainty of death. It is also indicated that anxiety is experienced by man in the face of awareness of his finitude, and this anxiety can be faced by an act of courage. It is resorted to the theoretical framework of Gestalt Therapy, which considers the fantasy of safety and avoidance of risk as possible neurotic adjustments, understood as obstacles to growth by avoiding contact with novelty. It also notes that the clinical practice of Gestalt therapy is not intended to offer an absence of risks to its clients, but, supported by the environmental support built in the therapeutic relationship, seeks to facilitate contact with the way these risks are lived, thus enabling the development of self-support.
\end{abstract}

Keywords: Security; Risk; Gestalt Therapy.

Resumen: El documento busca desarrollar una comprensión de los ajustes creativos para mantener el status quo y la seguridad y la imposibilidad o inexistencia de seguridad como libre de riesgos. A pesar de esta imposibilidad, la búsqueda de la seguridad y la evitación de riesgos son sorprendentes en la sociedad contemporánea y a menudo están presentes en la clínica psicológica. Esto a menudo se entiende como un espacio que proporcionará respuestas y seguridad en la imaginación tanto del buscador como del psicoterapeuta. Al reflexionar sobre el tema, buscamos establecer un diálogo entre las perspectivas sociológicas, la filosofía de Paul Tilich y las referencias teóricas de la Gestalt Terapia. Se argumenta que, desde las sociedades modernas, el conocimiento científico, incluida la psicología, se busca como una promesa de seguridad. Del trabajo de Paul Tilich, el riesgo se señala como inherente a la existencia, ilustrado por la certeza de la muerte. También se indica que el hombre experimenta ansiedad ante la conciencia de su finitud, y esta ansiedad puede enfrentarse mediante un acto de coraje. Se utiliza el marco teórico de la terapia Gestalt, que considera la fantasía de la seguridad y la evitación del riesgo como posibles ajustes neuróticos, entendidos como obstáculos para el crecimiento al evitar el contacto con la novedad. También señala que la práctica clínica de la terapia Gestalt no tiene la intención de ofrecer una ausencia de riesgos a sus clientes, sino que, respaldada por el apoyo ambiental construido en la relación terapéutica, busca facilitar el contacto con la forma en que se viven estos riesgos, permitiendo así El desarrollo de la autosuficiencia.

Palabras clave: Seguridad; Riesgo; Gestalt-terapia. 


\section{Introdução}

O interesse pelo tema da segurança surgiu a partir da observação de alguns fenômenos. Uma parte considerável dos clientes em psicoterapia busca na clínica psicológica informações, técnicas e recursos que lhes permitam se sentir seguros e protegidos. Tal necessidade de segurança e evitação dos riscos também é expressa em escolhas e modos de existência que lhes "garantam” tal sensação, mesmo que isso lhes custe crescimento, saúde ou autenticidade.

Também é possível perceber que muitas pessoas alienam partes de si mesmas para evitar conflitos e para não correr riscos, como o risco de não serem aceitas por seus pares, por exemplo. Em outros momentos, a busca por segurança implica na evitação de contato com elementos do ambiente que satisfariam necessidades importantes do organismo. Entendemos que a necessidade de segurança e evitação de risco é uma característica da sociedade contemporânea, e consequentemente dos modos de existência atuais, o que se revela pela permanente procura por terapias, saberes científicos, conteúdos de autoajuda, experiências místico-religiosas e relações interpessoais com o intuito de favorecer o sentimento de segurança.

Tal característica da sociedade contemporânea é analisada nas reflexões do sociólogo britânico Anthony Giddens (1991), que, em seu livro As Consequências da Modernidade, apresenta algumas ferramentas da modernidade ${ }^{1}$ que são formuladas para fornecer segurança, entre elas o saber científico - dispositivo fundamental do intento iluminista. O sociólogo britânico aponta que a insegurança está intimamente implicada na existência, asseverando que o ideal de segurança como ausência de riscos é falacioso.

A Psicologia e as Psicoterapias estão incluídas entre os saberes científicos que no imaginário social nos permitem a adoção de "manuais de vida" como recurso para a segurança e a evitação de riscos. Podemos encontrar na clínica clientes que explicitamente afirmam que desejam que os ensinemos a lidar com as angústias, frustrações, conflitos e impasses em suas vidas e, portanto, sirvamos como manuais.

Muitos outros clientes, mesmo que não verbalizem que desejam ou buscam segurança, “optam” por ajustamentos mais seguros, colocando fortes obstáculos ao seu crescimento e à satisfação de suas necessidades organísmicas, denunciando "um dos vários sintomas da estagnação do crescimento" (Perls, Hefferline \& Goodman, 1951/1997, p. 11) como diria Fritz Perls, na apresentação à edição de 1969 do livro Gestalt-terapia. É recorrente na clínica a experiência de pessoas que vivem relacionamentos (amorosos, laborais, familiares, etc.) pouco nutritivos e que, na evitação dos riscos que novas escolhas e experiências implicam, sustentam a relação mesmo que tal

1 Giddens (1991) nomeia a contemporaneidade de modernidade tardia, pois, para o autor britânico, as principais características da modernidade não foram superadas. Tais características permanecem presentes na contemporaneidade, tendo sido na verdade acentuadas. permanência comprometa a satisfação de outras necessidades e desejos. Observamos pessoas buscando modelos de relacionamentos interpessoais que lhes proporcionem segurança ou estabilidade, seja financeira ou afetiva. Tais experiências retratam o que denominamos de ajustamentos de manutenção do status quo e evitação de riscos. Adverte-se que, inspirado na compreensão de que a perspectiva gestáltica não é uma terapia de ajustamento, a formulação de uma nomeação que indica um modo de funcionamento que privilegia a manutenção do status quo e evitação de riscos não sugere que tais modos de funcionamento devem ser combatidos ou adjetivados negativamente, mas sim facilitar uma tomada de consciência sobre as condições de possibilidades que favorecem a sua constituição.

A busca por segurança pode ser observada em outros indicadores sociais, como a grande procura por concursos públicos, que se dá não pela identificação com a tarefa do cargo almejado, mas por causa da estabilidade oferecida pelos cargos públicos. Outro exemplo é a medicalização da vida, uma opção que sugere um caminho mais fácil e mais seguro, pela promessa de que o remédio produzirá um alívio mais rápido dos sintomas, permitindo assim que o sujeito não lide com o sentido destes e com as implicações que a consciência disso apresenta. Destacamos que em diversas situações o medicamento é efetivamente uma estratégia de produção de cuidado necessária para lidar com a experiência de sofrimento; chamamos a atenção para o modo caricato como vem se dando o uso indiscriminado do medicamento com o intuito de evitar o sofrimento.

Podemos perceber muitas pessoas buscando modelos e manuais de como viver a vida. Tal busca parece conter o objetivo de eliminar ou evitar a angústia e o risco da autoconstrução. Afloram pela cidade outdoors e panfletos de profissionais que afirmam poder oferecer fórmulas e orientações para o sucesso. Muitos projetos de vida são orientados pela busca por segurança, mais do que pelo desejo.

Também se multiplicam os tipos de experiências religiosas que sugerem a redução dos riscos de fracassar, da solidão, da rejeição e da condenação. Vale a pena destacar que a crença em um ser superior e criador comumente está associada à fé de que há uma verdade sobre si mesmo que antecede a existência. Tal verdade justifica a vivência de uma doutrina que regulamente a forma de viver daquele que crê. Em nome dessa promessa, muitas pessoas, seguindo a máxima de que "Quem obedece nunca erra”, abrem mão de sua espontaneidade e responsabilidade. Acrescenta-se ainda na dimensão das doutrinas religiosas a crença em uma vida após a morte que serve para minimizar a angústia de lidar com a finitude e com o risco do morrer.

Partindo de uma compreensão gestáltica, não cabe ao psicoterapeuta oferecer ao cliente recursos ou estratégias que o permitam alienar os riscos de 
sua existência, algo que seria impossível e equivocado. Entendemos que, na clínica gestáltica, propomo-nos a colaborar para que o cliente possa desenvolver autossuporte e, assim, ser responsivo nas diversas situações existenciais que indicam riscos. $\mathrm{O}$ desenvolvimento de autossuporte significa a apropriação de recursos para lidar com as próprias experiências, principalmente de sofrimento, com relativa autonomia em relação ao campo. Promover o autossuporte se torna imprescindível se considerarmos que, por uma perspectiva gestáltica, o cliente é responsável pela própria existência (Cardella, 2012).

Considerando a relevância da temática no âmbito de nossa cultura, marcada pela incessante busca de segurança sem o reconhecimento da impossibilidade de efetivamente alcançá-la, questionamos: Quais referências teóricas nos ajudam a responder essa problemática do risco e a necessidade de manutenção do status quo, tão característica da contemporaneidade? Ao assumirmos que organismo e ambiente são mutuamente constitutivos, quais aspectos da busca de manutenção do status quo está ligada à necessidade de conservação do organismo? Ou ainda, o apego ao status quo é um fenômeno do ambiente social em que vivemos, e que denuncia os contornos que facilitam modos-de-ser eminentemente neuróticos, no sentido de favorecer a evitação de riscos e a manutenção do status quo?

\section{Metodologia}

Para elaboração de uma compreensão sobre os fenômenos acima descritos, recorreu-se à produção de um ensaio. Para Meneghetti (2011), o ensaísta trabalha a partir de conceitos, aproximando-os ou afastando-os para construir um significado para a realidade. Nesse sentido, buscaram-se prioritariamente as noções de segurança e segurança ontológica da abordagem sociológica de Anthony Giddens (1991), os conceitos de coragem e ansiedade da abordagem filosófica de Paul Tillich (1976) e as categorias de segurança, autossuporte e heterossuporte, e neurose, a partir do referencial da Gestalt-terapia, principalmente fundamentando-nos nos autores Perls, Hefferline e Goodman (1951/1997).

Como podemos ver em Meneghetti (2011), os ensaios são importantes formas de produção do conhecimento, mas que não se enquadram nos moldes da ciência tradicional positivista. A produção de conhecimento do ensaio se caracteriza pela intenção de construção de um diálogo entre os autores e os leitores em que o conteúdo é mais importante do que um rigor metodológico cartesiano na produção do trabalho; em que as perguntas e reflexões são mais importantes do que as afirmativas positivistas pretensamente verdadeiras.

De acordo com Meneghetti (2011), o ensaio se apresenta como uma busca pela compreensão de um objeto de análise que não utiliza um "sistema de compreensão rígido” (Meneghetti, 2011, p. 325).
Para o autor, "a utilização de dados trabalhados estatisticamente ou coletados pelos métodos tradicionais de coleta de dados (entrevistas, questionários, observações participantes etc.) não são relevantes" (Meneghetti, 2011, p. 326); isto porque, segundo o autor, "no ensaio, o empírico já está apreendido pela consciência do ensaísta, e este reflete criticamente sobre o objeto." (Meneghetti, 2011, p. 326).

No ensaio, a pretensa objetividade da ciência tradicional dá lugar a uma relação da subjetividade do ensaísta com o objeto de análise, que passa a se tornar importante na compreensão do objeto do ensaio. Meneghetti (2011), ao refletir sobre em que consiste o ensaio teórico, recorre ao pensamento de Theodor Adorno, que, por sua vez, afirma que no ensaio os autores admitem a possibilidade do erro. Por se configurar como uma retratação de uma experiência que permanece em aberto, os autores assumem a falta de segurança que a norma do pensamento institucionalizado teme como se fosse a morte.

Parece coerente que um estudo que se propõe a refletir sobre a inexistência de uma segurança enquanto ausência de riscos não adote um método de exposição que tenha a pretensão de prometer certezas e seguranças, como observado no pensamento científico tradicional e positivista.

\section{O Binômio Segurança e Risco em Questão}

\section{Segurança, um enfoque sociológico}

Giddens (1991), ao definir segurança, apresenta-a como uma "situação na qual um conjunto específico de perigos está neutralizado ou minimizado. A experiência de segurança baseia-se geralmente num equilíbrio de confiança e risco aceitável" (Giddens, 1991, p. 37). Importante ressaltar nesse trecho que a própria definição do autor da experiência de segurança contempla o risco, o que corrobora a perspectiva por nós adotada de que a fantasia de uma segurança sem riscos é absolutamente ilusória.

Ainda corroborando a relação intrínseca entre segurança e risco, Giddens (1991, p. 35) nos fala que a "experiência de segurança" baseia-se na confiança, vivida como um ato de fé, pois

Não haveria necessidade de se confiar em alguém cujas atividades fossem continuamente visíveis e cujos processos de pensamento fossem transparentes, ou de se confiar em algum sistema cujos procedimentos fossem inteiramente conhecidos e compreendidos.

Giddens (1991) traz um outro conceito que entendemos ser importante para a presente discussão, a noção de segurança ontológica. Esta, para o sociólogo britânico, é "a crença que a maioria dos seres humanos tem na continuidade de sua autoidentidade e na constância dos ambientes de ação social e 
material circundantes" (Giddens, 1991, p. 84). A colocação nos remete ao contexto da contemporaneidade marcada pela permanente condição de crise, em que os regimes de verdade, ao serem questionados, não conseguem mais assegurar a forma como os sujeitos devem viver suas vidas. A partir dos horizontes simbólicos que lhe são possíveis, o sujeito é assim convocado a construir seu projeto de vida, o que implica uma responsabilidade pessoal sobre quais crenças e valores ele irá adotar nesse projeto.

Como podemos ver, em Giddens (1991), o sentimento de segurança se refere a uma crença no ambiente que circunda o organismo e também na continuidade de si mesmo. Não há referência no texto de Giddens de que a crença na continuidade da autoidentidade do sujeito se dê a partir de seu autossuporte, o que sugere que, a partir desse conceito, o sentimento de segurança deriva de uma confiança no suporte ambiental. Isso se confirma ainda mais se observarmos como Giddens compreende a construção da segurança ontológica.

Percebe-se aqui um ponto de diferenciação entre as reflexões do sociólogo britânico e as formulações teóricas em Gestalt-terapia. Na abordagem gestáltica, privilegia-se o desenvolvimento do autossuporte por entender que o sujeito não tem controle sobre o campo; o que lhe é possível é ser responsável (como habilidade de responder) frente às possibilidades que são percebidas nesse campo. Dessa forma, a Gestalt-terapia se diferencia do olhar de Giddens (1991) ao apresentar o entendimento de que o sentimento de segurança deriva de uma confiança no suporte ambiental - não desconsiderando que existem contextos sociais que são potencialmente mais privilegiados em favorecer esse sentimento de segurança - ao provocar o sujeito para que assuma uma condição de protagonismo frente a esse contexto social.

De acordo com Giddens (1991), a construção do sentimento de confiança ou segurança ontológica ocorre a partir de experiências da infância. Se a criança foi capaz de confiar na continuidade da proteção e do amor das figuras parentais apesar de eventuais ausências da presença dessas figuras, ela desenvolveu a atitude de confiança básica e segurança ontológica. Nas palavras de Giddens (1991, p. 88),

Um sentimento de segurança, contudo experiência independente, em relação aos outros central ao senso de continuidade da auto-identidade - é predicado sobre o reconhecimento de que a ausência da mãe não representa uma retirada do amor. A confiança, assim, equipara a distância no tempo e no espaço bloqueando, deste modo, ansiedades existenciais que, se pudessem se concretizar, poderiam se tornar uma fonte de angústia contínua, emocional e comportamental, através da vida.

Ao fazer um recorte das palavras de Giddens, podemos ser levados a compreender que a sensação de segurança ou sua ausência é causada por experiências na infância e pelo contexto familiar. Na perspectiva gestáltica, assumimos a importância que as experiências de vida têm na constituição dos sujeitos, dos seus modos de ser no mundo, e entendemos o lugar que as relações significativas possuem na vivência afetiva das pessoas, contudo entende-se que a experiência de um sujeito não é causada por algum evento no passado. Dessa forma, questionamos se assumir a perspectiva adotada por Giddens não implica em localizar no sujeito e suas famílias as "causas" do sentimento de insegurança, do temor à novidade, ao desconhecido. Interrogamo-nos em que medida tal perspectiva proposta pelo sociólogo britânico não contempla no fenômeno da construção do sentimento de segurança as questões sociais, e como tais atravessam e constituem os sujeitos. Destacamos que a abordagem gestáltica traz como fundamento a perspectiva de campo, que se materializa no conceito de campo organismo/ambiente sendo um elemento norteador da práxis gestáltica, tal como será discutido na sequência do texto.

Retomando a referência do pensamento do sociólogo britânico, destacamos que Giddens (1991) apresenta a noção de segurança ontológica indicando que esta tem um caráter emocional e subjetivo, e não objetivo. Para o autor britânico, o sentimento de segurança ontológica é fundamental para os sujeitos, contudo ele nos adverte sobre o caráter inextrincável da insegurança como parte da existência. De acordo com esse autor, "existem poucos, se é que existe algum, aspectos de nossa existência pessoal dos quais podemos estar certos" (Giddens, 1991, p. 84). Portanto, é possível experimentar a segurança subjetivamente, mas jamais se estar objetivamente seguro.

Embora o risco faça parte da existência, existem diferentes formas de se lidar com o risco ou de conviver com ele. Para Giddens (1991), a maioria das pessoas vive com o sentimento de segurança ontológica, apesar de não estar efetivamente segura. $\mathrm{Na}$ contemporaneidade, uma parcela significativa de pessoas experimenta esse risco com uma "intranquilidade profunda que penetra muitas das coisas que elas fazem" (Giddens, 1991, p. 85). Tal fato parece indicar muito mais uma condição de "supersensibilidade emocional do que de irracionalidade" (Giddens, 1991, p. 85). Fazendo um paralelo com nossas experiências clínicas com atendimento a pessoas que vivem experiências marcadas por ansiedade e fantasias catastróficas, percebemos que tais experiências de fato vinculam-se a uma condição de hipersensibilidade provocada pelo marcante estado de alerta por elas vivido, estando os sujeitos muitas vezes cientes de que seus temores não possuem uma lógica plausível racionalmente. Tais experiências parecem indicar uma hipersensibilidade aos riscos que vivemos enquanto existentes, hipersensibilidade que se traduz na possibilidade reduzida de defle- 
tir consciência sobre a real existência de tais riscos. A perspectiva que estamos defendendo sugere que existir implica riscos, e que em certa medida é necessário que o sujeito tenha consciência e assuma tais riscos, bem como em alguns momentos possa alienar a consciência de tais riscos para que possa viver outras figuras, outras experiências.

Assumindo uma perspectiva histórica, entendemos que cada contexto sociocultural lidou com os riscos inerentes aos seus modos de vida e organização social e buscou construir seus próprios dispositivos de segurança. Giddens (1991), ao discorrer sobre a modernidade, afirma que o "desenvolvimento das instituições sociais modernas e sua difusão em escala mundial criaram oportunidades bem maiores para os seres humanos gozarem de uma existência segura e gratificante que qualquer tipo de sistema pré-moderno" (Giddens, 1991, p. 13). Por outro lado, como demonstrado por Giddens (1991), as culturas pré-modernas ofereciam contextos de confiança que perderam sua eficácia na modernidade: as relações de parentesco, a comunidade local, as cosmologias religiosas e a tradição. De acordo com o autor britânico, outros contextos fornecedores de confiança surgiram na modernidade; entre eles destacamos as relações pessoais e os sistemas abstratos.

Já o sociólogo polonês Zygmunt Bauman (2004), ao apontar a categoria de Amor Líquido, discorre sobre a fluidez dos relacionamentos na modernidade, destacando que as relações pessoais não são fonte de confiança, mas de insegurança. Explicitando a fragilidade dos laços humanos na forma como se vive na contemporaneidade, Bauman (2004, p. 141) argumenta que os projetos urbanistas advindos da modernidade não foram eficazes em garantir a segurança pretendida por estes. Tal fracasso se mostra na incapacidade de

aliviar, muito menos erradicar, a insegurança existencial reabastecida diariamente pela fluidez dos mercados de trabalho, pela fragilidade do valor atribuído a habilidades e competências do passado ou que se busca adquirir no presente, pela reconhecida vulnerabilidade dos vínculos humanos e pela suposta precariedade e revogabilidade dos compromissos e parcerias.

As características da sociedade contemporânea acima descritas por Bauman (2004) se sobrepõem aos intentos de segurança que a sociedade moderna buscou fornecer. Nesse sentido, as relações interpessoais compartilham dessa característica de liquidez que marca a atualidade. Contudo, de acordo com o autor polonês, a segurança não deixa de ser algo buscado nesses mesmos relacionamentos. Bauman (2004, p. 29) apresenta a compreensão de que

se você investe numa relação, o lucro esperado é, em primeiro lugar e acima de tudo, a segu- rança - em muitos sentidos: a proximidade da mão amiga quando você mais precisa dela, o socorro na aflição, a companhia na solidão, o apoio para sair de uma dificuldade, o consolo na derrota e o aplauso na vitória; e também a gratificação que nos toma imediatamente quando nos livramos de uma necessidade.

Retomando o que Giddens (1991) aponta sobre os contextos fornecedores de confiança que surgiram na modernidade, o autor britânico discute que a religião deixou de ter a importância como regime de verdade de que outrora gozava e foi "suplantada pelo conhecimento reflexivamente organizado, governado pela observação empírica e pelo pensamento lógico, e focado sobre tecnologia material e códigos aplicados socialmente" (Giddens, 1991, p. 98). Nesse sentido, reconhece-se que a partir da modernidade o discurso religioso é majoritariamente substituído pelo conhecimento científico, que passa a ser apresentado como promessa para se obter segurança, sendo tomado como uma nova moralidade que orienta e normatiza a vida cotidiana. Giddens (1991, p. 40) nos apresenta a condição paradoxal do conhecimento científico ao afirmar que

estamos em grande parte em um mundo que é inteiramente constituído através de conhecimento reflexivamente aplicado, mas onde, ao mesmo tempo, não podemos nunca estar seguros de que qualquer elemento dado deste conhecimento não será revisado. Mesmo os filósofos que mais ferrenhamente defendem as reinvindicações da ciência à certeza, tais como Karl Popper, reconhecem que, como ele o exprime 'toda ciência repousa sobre areia movediça'. Em ciência, nada é certo e nada pode ser provado, ainda que o empenho científico nos forneça a maior parte da informação digna de confiança sobre o mundo a que podemos aspirar.

De fato, o conhecimento científico é continuamente revisado. Uma interessante amostra disso pode ser encontrada nas orientações dos cardiologistas e nutricionistas sobre a alimentação. Há momentos em que determinados alimentos são recomendados para se viver bem e com saúde, e posteriormente esses mesmos alimentos são considerados nefastos e vice-versa. Dessa forma, apesar de o saber científico ser buscado para fornecer segurança, não o pode fazer de forma categórica, o que sugere mais uma vez que a segurança definitiva não pode ser alcançada e que o risco inerente à existência não pode ser evitado.

Corroborando essa premissa de verdade de que os conhecimentos científicos gozam na contemporaneidade e as promessas de verdade e segurança que lhes são inerentes, percebemos notoriamente na experiência de algumas pessoas a procura por profissionais do campo psi, pelas práticas de coaching 
e mentoring que fornecem a promessa de crescimento, sucesso, felicidade, sendo dispositivos criados para enfrentar as incertezas. Ampliando a discussão sobre as contribuições e limites do conhecimento científico para nossa sociedade, o sociólogo britânico afirma que é

falsa a tese de que mais conhecimento sobre a vida social (mesmo que tal conhecimento esteja o mais empiricamente comprovado) é igual ao maior controle sobre nosso destino. Ela é (discutivelmente) verdadeira no que tange ao mundo físico, mas não ao universo dos eventos sociais. (Giddens, 1991, p. 43)

Entendendo que o fenômeno por nós problematizado do binômio segurança/risco constitui-se como essencialmente psicossocial, é imperativo questionar em que medida os conhecimentos produzidos pelas epistemologias psicológicas podem formular uma verdade última sobre tais fenômenos. Verdade esta que nos garantiria enquanto sujeitos e sociedade meios de superar as experiências marcadamente ansiogênicas.

\section{Segurança, um enfoque filosófico}

Na obra A Coragem de Ser, publicada pela primeira vez em 1952, o filósofo polonês Paul Tillich (1976) também aponta o risco como inerente à existência. Para o autor polonês, a consciência da negação do ser é experimentada como ansiedade. Considerando que a vida é finita e que todos têm a certeza da morte, e considerando que isso pode ocorrer a qualquer instante, todos estão sujeitos à ameaça do não-ser, à ameaça de morte, por exemplo. A consciência do não-ser é experimentada como ansiedade, que, de acordo com Tillich (1976), faz parte da existência mesma. A ameaça do não-ser é, portanto, um risco e a consciência disso é sentida como ansiedade, o que nos remete à reflexão de Giddens (1991, p. 85) de que aqueles que estão demasiada e emocionalmente sensíveis aos riscos de suas existências experimentam uma "intranquilidade profunda", o que podemos verificar na experiência clínica com pacientes ansiosos.

De acordo com Tillich (1976), a ansiedade pode ser enfrentada se o eu é capaz de afirmar-se e tomar sobre si essa ansiedade, destacando a coragem de ser como o ato de afirmação da parte mais essencial de uma pessoa. Essa afirmação ou ato de coragem que pode enfrentar a ansiedade pode se dar de várias formas, sendo uma delas a coragem por participação em uma sociedade ou a coragem de ser como uma parte $^{2}$. Contudo, embora a maioria das instituições

2 Tillich (1976) define "coragem de ser como uma parte" como o ato de afirmação da essência de um indivíduo por meio de sua participação em uma sociedade ou grupo a que faz parte. Para o filósofo polonês, "a coragem de se afirmar como indivíduo" e a "coragem de ser como uma parte" se constituem mutua e interdependentemente. Disso decorre que a própria individualidade só pode ser afirmada e constituída em relação com outras pessoas, grupos e o campo em que está inserido o indivíduo. da civilização sirva para fornecer segurança ao ser humano, em períodos de crise e grandes transições, os métodos disponíveis em uma sociedade para conter a ansiedade não funcionam e a ansiedade se generaliza.

Importante ressaltar que a busca por segurança, para Tillich (1976), não é necessariamente patológica desde que não implique na evitação de riscos, o que a torna de certa forma paradoxal. De acordo com Tillich (1976, p. 58), "a ansiedade do destino e da morte produz esforços não patológicos pela segurança”. Porém, ainda segundo o filósofo polonês, a plena autoafirmação do indivíduo requer a renúncia a alguma, senão a toda, segurança. Em outro trecho, Tillich (1976, p. 62) afirma que "o impulso para a segurança, perfeição e clareza, ao qual nos referimos, é biologicamente necessário. Porém, se torna biologicamente destrutivo se o risco de insegurança, imperfeição e incerteza é evitado”.

Tillich (1976) traz uma diferenciação entre medo e ansiedade que pode ser importante para entendermos a relação entre esses estados emocionais e a coragem. Essa relação, por sua vez, é importante na medida em que consideramos os sentimentos comuns diante dos riscos inerentes à existência, como medo e ansiedade. Lembramos aqui que, partindo de uma concepção gestáltica, emoções ou sentimentos são fenômenos de um campo organismo/ambiente. O filósofo polonês destaca que, enquanto o medo tem um objeto específico, a ansiedade não tem um objeto definido, e a forma de um sujeito enfrentar a ansiedade consiste na tentativa de transformação desta em um objeto definido a despeito do qual o eu pode afirmar-se, em um ato de coragem. Nas palavras de Tillich (1976, p. 52),

a ansiedade tende a tornar-se medo, visando ter um objeto com o qual a coragem possa bater-se. A coragem não afasta a ansiedade. Uma vez que a ansiedade é existencial, não pode ser afastada. Mas a coragem incorpora a ansiedade dentro de si.

Para o referido autor, quando uma pessoa não consegue incorporar a ansiedade dentro de um ato de autoafirmação ou coragem, evita o desespero a partir da neurose. Nas palavras do autor,

aquele que não obtém êxito em tomar com coragem sua ansiedade sobre si próprio, pode obter êxito em evitar a situação extrema do desespero escapando para a neurose...Neurose é o meio de evitar o não-ser evitando o ser. (Tillich, 1976, p. 52)

Em outro trecho, Tillich (1976, p. 60) afirma que "a ansiedade patológica é a falência do eu em tomar a ansiedade sobre si" e ainda que 
A ansiedade patológica ante o destino e a morte impele a uma segurança que é comparável à segurança de uma prisão. Quem vive nesta prisão é incapaz de deixar a segurança que lhe é dada por suas limitações auto-impostas. Mas estas limitações não são baseadas numa plena consciência da realidade. Portanto, a segurança do neurótico é irrealista. Ele teme o que não deve ser temido e sente como seguro o que não é seguro. A ansiedade, que ele não é capaz de incorporar a si próprio, produz imagens sem base na realidade, mas se apaga frente a coisas que deveriam ser temidas. Isto é, evitam-se perigos determinados, embora sejam raras vezes reais, e suprime-se a certeza de ter de morrer, ainda que isto seja uma realidade sempre presente. Medo deslocado é uma consequência da forma patológica da ansiedade do destino e da morte. (Tillich, 1976, p. 58)

A partir desse trecho, podemos compreender que a busca por segurança torna-se patológica quando implica na evitação do risco, constituindo-se como uma evitação de si mesmo, evitação de sua própria existência. Essa segurança tem, portanto, um preço alto. Com o intuito de escapar da ansiedade, do risco do não-ser, algumas pessoas abrem mão da liberdade, por exemplo, como afirma Tillich, e essa segurança se configura como uma prisão.

Os conceitos de Tillich (1976) podem nos ajudar a elaborar uma reflexão sobre a coragem e o sentimento de segurança como ajustamentos criativos de um campo organismo/ambiente. De acordo com Tillich (1976, p. 55), "há um momento em que a auto-afirmação do homem comum se torna neurótica: quando mudanças na realidade a qual está ajustado ameaçam a coragem fragmentária com a qual ele tem dominado os costumeiros objetos de medo". Segundo o filósofo polonês, isso ocorre frequentemente em períodos de crise da história e "os perigos relacionados com a mudança, o caráter desconhecido das coisas por vir, a escuridão do futuro fazem do homem comum um fanático defensor da ordem estabelecida" (Tillich, 1976, p. 55). Tal reflexão nos permite inferir que as transformações sociais - em especial as transformações dos papéis de gênero, das representações de família, a perda do referencial religioso como discurso moral unívoco e das promessas de proteção divina e salvação, a falência da confiança no Estado e nas representações políticas-partidárias - estão relacionadas com as demandas das clínicas psicológicas e medicamentosas das experiências de ansiedade e com o levante de discursos sociais em nome da tradição religiosa, do modelo biológico de família e outros, que buscam aplacar a ansiedade que as incertezas sociais produzem.

Se entendermos, como Tillich, que mudanças na realidade podem afetar a afirmação de uma pessoa e ainda a tornar defensora do status quo, pode- mos perceber o sentimento de segurança do campo organismo/ambiente coerente com uma perspectiva de campo encontrada na abordagem gestáltica. Apresentamos o sentimento de segurança como sendo do campo organismo/ambiente porque, a partir do referencial gestáltico, organismo e ambiente se constituem mutuamente e formam um todo indivisível. Na verdade, organismo e ambiente são abstrações de uma realidade efetivamente originária, o contato. Organismo e ambiente estão de tal modo imbricados no campo organismo/ambiente que não se pode conceber um a não ser em relação com o outro (Perls et al., 1951/1997). O sentimento de segurança, portanto, não é interno ou reservado ao organismo, mas expressa uma relação do campo organismo/ambiente. Embasados por esta compreensão de campo podemos entender a contribuição de Tillich de que mudanças no contexto em que vive um indivíduo são importantes no posicionamento deste indivíduo diante de riscos e de sua afirmação como ato de coragem.

Partindo da compreensão de campo e das contribuições de Tillich apresentada acima, podemos ainda retomar a discussão entre o uso de suporte ambiental e de autossuporte e da importância do desenvolvimento do último. Se, como vimos acima, o suporte ambiental pode não estar disponível e de fato a sua disponibilidade é imprevisível, então se torna salutar o desenvolvimento de autossuporte para o ato de coragem ou para a afirmação de si.

\section{Segurança, um enfoque gestáltico}

Perls et al. (1951/1997), no livro Gestalt-terapia, publicado originalmente em 1951, elucidam que "o que temos que entender é que não existe algo como uma segurança verdadeira, porque nesse caso o self seria uma fixidez" (Perls et al., 1951/1997, p. 218). Isso quer dizer que, se existisse uma segurança verdadeira, sem riscos, não haveria novidades no campo organismo/ambiente, condição necessária ao crescimento, conservação e renovação do organismo.

Em nosso intento de refletir sobre o binômio segurança e risco, recorremos à colocação de Perls et al. (1951/1997) quando nos apresentam que frente ao risco é possível a crença no suporte ambiental, é possível agir com fé. No sentido empregado por Perls et al. (1951/1997, p. 151), fé consiste em "saber, para além da awareness, que se dermos um passo haverá um chão sob nossos pés: entregamo-nos sem hesitação à ação, temos fé de que o contexto gerará os meios”. O contrário da fé, para Perls et al. (1951/1997), seria a experiência de apego à segurança, entendido aqui como situações que supostamente não ofereçam riscos. De acordo com os referidos autores, "o que ordinariamente denomina-se 'segurança' é apegar-se ao não percebido, recusando-se o risco do desconhecido implicado em qualquer situação absorvente" (Perls et al., 1951/1997, p. 47). A fé descrita nesses termos se assemelha, portanto, a 
uma confiança, que ainda que seja vivida pelo organismo, é um evento do campo, se constitui na relação, na medida em que os recursos que o sujeito dá conta de mobilizar são percebidos e coincidem com as possibilidades do ambiente, admitindo-se que ainda há riscos inerentes a situação concreta vivida.

A confiança descrita acima pode ser tomada como o sentimento de segurança ontológica exposto anteriormente, ou como uma sensação de segurança. Assim como Giddens (1991), Frazão (2015) aponta a sensação de segurança como construída a partir da relação da criança com os pais e o desenvolvimento ulterior da criança. A autora afirma que

a mãe, por meio de sua awareness, pode captar empaticamente seu bebê, percebendo suas necessidades. Uma vez que é ela que, a um só tempo, supre as necessidades fisiológicas e está junto do filho amorosa e respeitosamente, ela é o primeiro outro significativo com quem a criança tem contato; constitui a primeira e mais importante possibilidade de estabelecimento de relação, sendo nesse campo relacional mãe-bebê que terá início o processo de desenvolvimento. Pouco a pouco, à medida que desenvolva autossuporte e se sinta segura, a criança poderá ampliar seu contato com o mundo, ampliando cada vez mais o âmbito e a complexidade de suas experiências. (Frazão, 2015, p. 87)

De acordo com Frazão (2015), se a satisfação de necessidades da criança está precoce e constantemente em rivalidade com a manutenção da relação com a mãe, a criança produzirá ajustamentos criativos disfuncionais e então

a relação que a criança mantém com sua mãe em lugar de segurança favorecerá o surgimento de desamparo e insegurança, interferindo na qualidade e na possibilidade de desenvolvimento das potencialidades da criança e na ampliação do âmbito e da complexidade de suas experiências. (Frazão, 2015, p. 91)

Assim como vimos em Giddens (1991), para quem o saber científico é convidado a oferecer segurança e certezas, também podemos ver que Perls et al. (1951/1997, p. 200), ao apresentarem uma discussão sobre o medo da criatividade, e portanto um medo do novo, sinalizam que as pessoas "consultam manuais, autoridades, colunistas de jornais e a opinião pública”. Frente às incertezas, costumamos buscar a segurança no ambiente, nas figuras de autoridade, nos peritos, sendo o saber científico uma garantia.

A relação de uma pessoa com a segurança e o risco se manifesta também em nível corporal. De acordo com as pesquisas de Lipton (2007), o funcionamento fisiológico do corpo em estado de proteção contra riscos é antagônico ao funcionamento que permite crescimento, sendo descrito que existe uma alteração da irrigação do cérebro para que sejamos capazes de elaborar respostas mais rápidas e instintivas, em detrimento de respostas cognitivas complexas. $\mathrm{O}$ antagonismo entre o estado de proteção contra riscos e o funcionamento que permite crescimento pode ainda ser compreendido se lembrarmos das reações fisiológicas que caracterizam a situação de luta ou fuga. Diante de um perigo intenso, a irrigação sanguínea priorizará os sistemas musculares, que facilitam fugir ou lutar, em detrimento do sistema digestório, que possibilita a nutrição. Tal assertiva nos remete à metáfora do metabolismo mental e à compreensão de Perls et al. (1951/1997) de que o organismo cresce pela assimilação da novidade.

Essas compreensões sobre o funcionamento do corpo diante de perigos se apresentam como elucidativas, se considerarmos que o organismo é um todo integrado e a totalidade do organismo se expressa no corpo. Isso pode ser verificado na clínica, onde podemos observar expressões corporais específicas de quem está se defendendo, como o retesamento dos músculos para inibição de contato.

Como podemos ver em Perls et al. (1951/1997), o organismo cresce e se conserva a partir da assimilação da novidade. Nesse sentido, se para se conservar o organismo deixa de correr riscos, como poderá entrar em contato com a novidade e então se conservar e crescer? A evitação de riscos pode, portanto, apresentar-se como uma inibição de contatos nutritivos, o que paradoxalmente não deixa de ser um ajustamento criativo diante dos riscos e dos recursos de suporte do campo e de autossuporte.

Perls et al. (1951/1997, p. 160), ao exporem uma compreensão sobre o conflito na neurose, afirmam que "a neurose pode ser considerada uma auto-conquista" com o objetivo de evitar um conflito que poderia mudar o status quo. A compreensão da evitação de conflitos e sua relação com a segurança já é sinalizada na obra Ego, fome e agressão, na qual Perls (1942/2002) afirma que, para evitar conflitos e permanecer em segurança, um indivíduo pode alienar parte de sua personalidade e sacrificar inclusive a própria individualidade. Tal perspectiva é destacada também por Belmino (2014), que entende a neurose como uma evitação.

A evitação de conflitos bem como a evitação de material novo presente no ambiente implicam na redução do exercício da criatividade própria de novos ajustamentos no campo organismo/ambiente. Sobre isso, Perls et al. (1951/1997, p. 218) esclarecem que "a timidez em ser criativo" tem como fonte a dor do "próprio excitamento crescente" e o medo de produzir mudanças. Os autores afirmam ainda que o apego ao status quo e aos ajustamentos realizados no passado proporciona uma impressão de segurança, que, como vimos, é falsa. Para os referidos autores, "a energia do apego ferrenho ao status quo provém 
das situações inacabadas que ainda tendem a se completar" (Perls et al., 1951/1997, p. 218).

De acordo com Perls et al. (1951/1997, p. 218),

a pessoa segura está empregando suas faculdades numa luta segura e sem surpresas com suas identificações inassimiladas. A luta prossegue e excita os sentimentos porque a situação que está inacabada se repete; mas se trata de um sentimento 'seguro' porque nada novo surgirá e já se sofreu a derrota. Semelhante luta também é segura; não pode ser concluída porque o organismo continua produzindo a necessidade; mas a agressão não se voltará para o ambiente, onde uma solução poderia ser encontrada.

A descrição acima sugere a possibilidade de compreensão do apego ao status quo a partir de inibições do processo de contato. A luta acima descrita contra identificações inassimiladas claramente se refere a uma luta contra introjetos. A introjeção, como podemos ver em Perls (1977) e em Perls et al. (1951/1997), consiste na identificação com valores, crenças ou atitudes que não podem ser assimilados, em outras palavras, é engolir por inteiro. A introjeção é neurótica desde que impeça ou dificulte o excitamento necessário ao bom contato. A descrição da agressão que não se volta contra o ambiente também indica mais uma interrupção do processo de contato.

Observemos agora como poderíamos compreender o apego ao status quo a partir das interrupções de contato de confluência. A confluência neurótica é descrita por Perls et al. (1951/1997, p. 252) como um

apegamento a inconsciência, como se estivéssemos nos apegando a um comportamento consumado para obter satisfação, e como se a nova excitação fosse roubá-lo; mas naturalmente, já que esse outro comportamento foi consumado e é costumeiro, não há nenhuma satisfação consciente nele, mas somente uma sensação de segurança. O paciente cuida para que nada de novo aconteça, mas não há nenhum interesse ou discernimento no que é antigo.

A descrição no trecho acima de uma confluência neurótica nos recorda da prática clínica, que nos permite identificar nas experiências dos clientes uma evitação dos riscos de algo novo e o apego a ajustamentos mais seguros, ainda que estes não sejam nutritivos. A compreensão da confluência neurótica como uma interrupção do contato e dos riscos inerentes a ele nos permite esclarecer de que forma clientes que se apegam a ajustamentos de evitação de riscos se encontram em situações menos nutritivas. Ao confluir com o consumado e evitar o surgimento de algo novo, aquele que conflui de forma neurótica deixa de entrar em contato com material novo do campo em que está inserido, material que poderia ser mais nutritivo, considerando suas necessidades organísmicas.

A confluência, ainda que seja uma interrupção do contato, não é necessariamente neurótica. De acordo com Perls et al. (1951/1997), há várias assimilações com as quais o organismo está confluente de forma saudável, que servem de fundo para a experiência consciente. A diferença entre a confluência saudável e a neurótica é que a confluência saudável pode ser contatada e serve como fundo para emersão e energização de uma figura, e a confluência neurótica consiste na fixação do fundo, impedindo o desenvolvimento de uma nova configuração figura/fundo.

A compreensão de confluência saudável e neurótica apresentada elucida uma relação entre segurança e risco, considerando que segurança enquanto ausência de riscos não existe, e o risco é inerente à existência. A sensação de segurança, enquanto permite e tolera o risco, ou seja, a segurança ontológica ou a fé, é saudável, pois permite o desenvolvimento de uma nova configuração figura/fundo e o crescimento e conservação do organismo. $\mathrm{O}$ apego à segurança, enquanto uma fixação do fundo, impedindo o excitamento e a energização de uma nova figura e impedindo o risco envolvido em toda novidade necessária ao crescimento por meio da assimilação, é, portanto, neurótico.

Diante desse apego à segurança que dificulta o crescimento, a psicoterapia se apresenta como ferramenta de cuidado e facilitação do crescimento do cliente. O papel da terapia consiste em fornecer um suporte para o cliente que possibilite o desenvolvimento de um autossuporte do último (Andrade, 2014). Como vimos acima, Frazão (2015) sinaliza que o desenvolvimento da confiança em si mesmo e do autossuporte deriva de uma situação de confiança em suporte ambiental. A transição da dependência do suporte ambiental para o apoio no autossuporte envolve um risco. Deixar um apoio em busca de outro é dar um passo ao desconhecido que emerge na experiência (Andrade, 2014).

O terapeuta tem como função colaborar para a construção de um setting relativamente seguro em que o cliente possa ter fé, ou seja, confiar e se permitir entrar em contato com aquilo que dificulta seu crescimento. Isso não significa eliminar os riscos da existência do cliente. Caberá também ao terapeuta frustrar de forma habilidosa o cliente, convidando-o a apoiar-se em seus próprios recursos e ter fé e confiança em si mesmo. Isso implicará em correr riscos e se identificar com suas capacidades criativas de estar no mundo.

\section{Considerações Finais}

Refletir sobre o binômio segurança e risco nos parece ser uma questão significativa no campo da clínica. Tal questão vem se apresentando tanto nas experiências que os sujeitos nos compartilham nesse espaço de escuta, bem como naquilo que a princípio é 
demandado da psicoterapia, pois esta, sendo tomada como uma representante da técnica, supõe-se que poderá garantir tal segurança. Nesse sentido, um desafio inicial de nossa prática é o de superar essa representação inicial que elege os saberes psicológicos como capazes de fornecer os desejados "manuais de vida", como recurso para a segurança e a evitação de riscos.

Pretendemos iniciar uma reflexão sobre o impacto que o binômio segurança e risco tem nos modos de organização social contemporâneos e nos respectivos modos de produção de subjetividades, interrogando sobre as implicações que a necessidade de segurança e evitação de riscos tem em nossos modos de existência e de que forma a abordagem gestáltica responde a essas questões.

Entendemos ser imprescindível assumir uma práxis psicológica que se apresente como recusa a essa lógica técnica, que fantasiosamente pensa garantir tal segurança. Pensamos ser a tarefa da psicoterapia um desafio outro, de acolher esse sujeito em sua experiência, facilitando a tomada de consciência do que em sua vida é vivido como risco e que, consequentemente, mobiliza um estado de alerta e uma tentativa de construir modos de ter controle, modos de evitação de risco. Em uma perspectiva de campo, é necessário refletirmos que o momento atual de transformação dos valores, crenças e estruturas sociais implica em muitos indivíduos uma vivência de crise, tendo em vista os impactos de tais transformações em nossas vivências temporais, espaciais, interpessoais, em nossos corpos. A Psicologia pode contribuir no sentido de facilitar a tomada de consciência dos desafios que tais mudanças sociais e dos padrões culturais mobilizam nos sujeitos.

Pretendemos evidenciar que, apesar do que almeja a cultura contemporânea, a extinção do risco existencial é um intento falacioso, sendo o risco um elemento constitutivo, inerente à existência. Nesse sentido, nossa prática clínica se fundamenta no axioma da clínica gestáltica de que o contato com aquilo que, em seu campo existencial, mobiliza os sentimentos de risco é provocador para elaboração de respostas criativas e o desenvolvimento de autossuporte, este significando a apropriação de recursos para lidar com as próprias experiências, principalmente de sofrimento, com relativa autonomia em relação ao campo. Assim, a clínica gestáltica não se propõe a assegurar o sujeito de que ele não correrá riscos, mas pode contribuir para o desenvolvimento de um sentimento de confiança que permita o contato com o novo e o consequente crescimento do organismo.

\section{Referências}

Andrade, C. C. (2014) Autossuporte e Heterossuporte. Em: Frazão, L. M., Fukumitsu, K. O., Costa, V. E. S. M., Schillings, A., Cardella, B. H. P., Andrade, C. C., ... \& Lima, P. Gestalt-terapia: conceitos fundamentais (Vol. 2). Summus Editorial.
Bauman, Z. (2004). Amor Líquido: sobre a fragilidade dos laços humanos. Rio de Janeiro: Zahar.

Belmino, M. C. (2014). Duas Faces da Gestalt Terapia. Fortaleza: Premius.

Cardella, B. H. P. Suporte. In: D’Acri, G., Lima, P., \&Orgler, S. (Eds.). (2012). Dicionário de Gestalt-terapia:" gestaltês". Summus Editorial.

Frazão, L. M. (2015). Compreensão clínica em Gestalt-terapia: pensamento diagnóstico processual e ajustamentos criativos funcionais e disfuncionais. Em L. M. Frazão \& K. O. Fukumitsu (Orgs.), $A$ clínica, a relação psicoterapêutica e o manejo em gestalt-terapia (pp. 83-102). São Paulo: Summus.

Giddens, A. (1991). As consequências da Modernidade. São Paulo: Unesp.

Lipton, B. H. (2007). A Biologia da Crença. São Paulo: Butterfly.

Meneghetti, F. K. (2011). O que é um Ensaio-Teórico? Revista de Administração Contemporânea, 15(2), 330-332. Recuperado em Fevereiro de 2018, de http://www.scielo.br/scielo.php?script=sci_arttext\&pid=S1415-65552011000200010

Perls, F. (1977). A Abordagem Gestáltica e Testemunha Ocular da Terapia ( $\left.2^{\mathrm{a} e d}\right)$. Rio de Janeiro: Zahar.

Perls, F. (2002). Ego, Fome e Agressão: Uma revisão da teoria e do método de Freud. São Paulo: Summus.

Perls, F., Hefferline, R., \& Goodman, P. (1997). Gestalt-terapia. São Paulo: Summus.

Tillich, P. (1976). A Coragem de Ser. Rio de Janeiro: Paz e Terra.

Rafael Cidrão Campos (orcid.org/0000-00023108-6674). Possui graduação em Psicologia pela Universidade de Fortaleza. Mestre em Psicologia pelo Programa de Pós-Graduação em Psicologia da Universidade de Fortaleza. Gestalt-terapeuta pelo Instituto Gestalt do Ceará. Email: rafaelcidrao@ hotmail.com

João Vitor Moreira Maia (orcid.org/0000-00032497-3977). Possui graduação em Psicologia pela Universidade Federal do Ceará. Mestre e Doutor em Psicologia pelo Programa de PósGraduação em Psicologia da Universidade Federal do Ceará. Gestalt-terapeuta pelo Instituto Gestalt do Ceará. Email: jv_psi@yahoo.com.br

Recebido em 01.08.18 Primeira decisão editorial em 08.08.19 Aceito em 17.12.19 